\title{
Detection of ionospheric anomalies during intense space weather over a low-latitude GNSS station
}

\author{
G. Sivavaraprasad ${ }^{1}$ D. Venkata $\operatorname{Ratnam}^{1}$ (D) R. Sree Padmaja ${ }^{1}$. \\ V. Sharvani ${ }^{1}$ G. Saiteja ${ }^{1}$ Y. S. R. Mounika ${ }^{1}$ P. Babu Sree Harsha ${ }^{1}$
}

Received: 5 April 2016/Accepted: 30 November 2016/Published online: 21 December 2016

(C) Akadémiai Kiadó 2016

\begin{abstract}
The operational availability of Global Navigation Satellite System is affected by large-scale irregularities of the ionosphere. The space weather events induce several intense irregularities and cause the non-linear distribution of ionospheric electron density. Monitoring of ionospheric responses due to extreme space weather events plays a key role in trans-ionospheric radio wave propagation. In the present analysis, a novel technique based on wavelet transform has been implemented for the analysis and detection of ionospheric anomalies during two intense space weather events that occurred in 2013. The investigations have been carried out using the ionospheric observable, Total Electron Content (TEC), derived from the Global Positioning System (GPS) receiver located at an Equatorial Ionisation Anomaly region, KL University, Guntur, India (Geographic Lat. $16.37^{\circ} \mathrm{N}$, Geographic Long. $80.37^{\circ} \mathrm{E}$ ). The effects of geomagnetic storms (Sym$\mathrm{H} \leq-100 \mathrm{nT}$ ) on the perturbations of ionospheric TEC have been investigated. The algorithm of Continuous wavelet transform has been used to study and characterise the presence of ionospheric anomalies in the local time-scale plane. It can detect spatial and temporal details of ionospheric anomaly intensity during strong solar-terrestrial and geophysical events. It is observed that during the main phase of the geomagnetic storm that occurred during 17 March 2013, TEC enhanced by 7 TECU, while a suppression of 10 TECU in the GPS-TEC can be noticed during the main phase of the 29 June 2013 storm. The variation in the intensity of ionospheric TEC anomalies during storm time has been detected and compared to the intensity of the space weather events measured through solar and geomagnetic indices (F10.7, Sym-H, IMF Bz and IEF Ey).
\end{abstract}

Keywords GPS · Ionosphere - Geomagnetic storms · Continuous wavelet transform · Detection of Anomaly · IRI model

D. Venkata Ratnam

dvratnam@kluniversity.in

1 Department of Electronics and Communication Engineering, KL University, Guntur, Andhra Pradesh, India 


\section{Introduction}

The upper atmospheric layer (ionosphere) ranges from 60 to $1000 \mathrm{~km}$, and is a significant part of the earth's environment and space weather. The complex nature of ionosphere influences the Global Positioning System (GPS) radio links. The parameters such as ionospheric F2 layer critical frequency (foF2), electron density and Total Electron Content (TEC) describe the state of the ionosphere. However, these parameters show regular diurnal and seasonal variations as a function of altitude, geographic coordinates and geomagnetic conditions (Rees 1989). Electrodynamics, the neutral composition of the atmosphere, and solar and geomagnetic activities are major drivers of short-term or longterm anomalies in different scales of ionospheric parameters (Kumar and Singh 2011a; Rishbeth and Mendillo 2001). The ionospheric anomalies can be categorised into three groups according to size, (a) large-scale (>10 km); (b) medium-scale $(0.1-10 \mathrm{~km})$ (c) small-scale $(<100 \mathrm{~m})$ (Yeh and Liu 1982; Vickrey and Kelley 1983; Kelley 1985). The large-scale ionospheric irregularities and the associated TEC fluctuations can increase the number of uncorrected and undetected cycle slips by complicating the phase ambiguity resolution, which causes losses of lock in GNSS signal (Wanninger 1992; Jakowski et al. 2005; Cherniak et al. 2014). Small and medium-scale irregularities cause phase and amplitude scintillations by a diffraction mechanism (Aarons and Basu 1994; Hunsucker and Hargreaves 2007). The sudden dissipation of faster Coronal Mass Ejections (CMEs) from the Sun triggers geomagnetic storms by depositing the energy of solar wind in the magnetospheric polar cap region. Thus, geomagnetic storms develop rapid changes in the magnetospheric convection currents, which lead to anomalies in ionospheric TEC; this is especially observed over equatorial and low-latitude regions (Buonsanto 1999; Sastri et al. 1997). The GPS receiver provides TEC information for monitoring a large area of the ionosphere simultaneously (Mannucci et al. 1993; Langley 1996).

The characteristics such as amplitude and phase of GPS signals are modified by the ionospheric anomaly, which effects precision of the satellite-based radio positioning and navigation systems. Large gradients have been observed in the ionospheric TEC during different intense geomagnetic storm events at various geographical locations over lowlatitude regions (Chakraborty et al. 2015; Jain et al. 2010; Mukherjee et al. 2010). The perturbations in the ionosphere attributed to high solar activity and geomagnetic storms cause abnormal features and anomalies with complex structures in the ionospheric TEC data (Dashora and Pandey 2007; Jain et al. 2010; Malik et al. 2010). The impact of geomagnetic storm (November 8 and 12, 2004) disturbances on the GPS-TEC gradients at different Indian latitudes has been investigated by Rama Rao et al. (2009). The mitigation of the ionospheric effects on the GPS radio wave propagation is difficult during quiet and disturbed states of geomagnetic activity. Therefore, the standalone GPS receivers are augmented with the aid of Satellite-Based Augmentation Systems (SBAS) in order to improve their precise positioning and surveying applications such as aircraft navigation. India has implemented its Satellite-Based Augmentation System (SBAS), the GPS- Aided GEO Augmented Navigation (GAGAN) system, which has been providing error corrections since 2014. However, the detection of small-scale ionospheric anomalies is an arduous task due to the dynamic behaviour of the Indian low-latitude ionosphere and a limited number of monitoring stations. Therefore, the detection and analysis of the complex and heterogeneous structures in ionospheric TEC anomalies recorded during ionospheric disturbances are most important for space weather prediction. The traditional methods are rather inadequate as they require a priori data in detecting anomalies in the 
time series (Mandrikova and Bogdanov 2007). The ordinary procedures are based on smoothing processes and do not allow one to explore subtle features of the ionosphere. Several algorithms have been implemented using $\chi^{2}$-based tests to detect the ionospheric disturbances (Sarma et al. 2009; Zhang et al. 2005). The Fast-Fourier Transform (FFT) Averaging Ratio (FAR) algorithm has been implemented to detect the GPS satellites, which are affected by low-latitude ionospheric irregularities (Raghunath and Ratnam 2015). In FAR algorithm, the ratio of averaged Power Spectral Densities (PSDs) of every satellite to the average across all satellite links is used to quantify the disturbance level on each individual satellite link. The drawback of FAR algorithm is that it may not be able to detect the affected GPS satellites when the signals from most of them are corrupted by the irregularities in the ionosphere. The parameter Rate of TEC index (ROTI) is commonly used as a statistical measure for the level of ionospheric irregularities. However, ROTI validity varies strongly with its sample rate, geographical latitudes, and other factors (Jacobsen 2014). Wavelet transformations have the ability to analyse the time series with a complex structure (Chui 1992; Daubechies 1992; Mallat 1999). Wavelet transform can be used to determine and detect the anomalies in ionospheric parameters (Mandrikova et al. 2014, 2015a, b). The multiscale analysis uses Continuous wavelet transform (CWT) to register the local characteristics in the complex structures of ionospheric TEC.

In this paper, the response of ionosphere during the adverse space weather events that occurred in March and June 2013 over the Indian EIA region, Guntur (Geographic. Lat. $16.37^{\circ} \mathrm{N}$; Geomagnetic. Lat. $7.50^{\circ} \mathrm{N}$ ) has been investigated. The CWT processes storm time GPS-TEC data for multiscale analysis (MSA) and to detect the ionospheric anomalies. The positive and negative scale anomalies have been highlighted during both the positive and negative storm phases that occurred in the year 2013, solar maximum period of 24th solar cycle.

\section{Experimental data for analysis}

A GNSS Ionospheric Scintillation and TEC Monitor (GISTM) receiver (Model: GPStation6, Make: NovAtel, Canada) has been in operation at KL University, Guntur (Geographic lat: $16.37^{\circ} \mathrm{N}$ and long: $80.37^{\circ} \mathrm{E}$ ), Andhra Pradesh, India. The Slant TEC (STEC) is obtained from the receiver, with the mask angle set as 50 degrees in the conversion of STEC into Vertical TEC (VTEC) using a planar fit model (Sarma et al. 2009). Importantly, at elevation angles greater than 50 degrees, errors due to multipath effects can be avoided in the TEC observations (Rao et al. 2006a, b). International Reference Ionosphere (IRI) model is a widely used empirical model, which provides monthly median values of ionospheric parameters (Bilitza 2001; Bilitza et al. 2014). The TEC values derived from the IRI-2012 model have been obtained from http://IRI.gsfc.nasa.gov. The geomagnetic indices such as F 10.7 index, Sym-H, IEF Ey and IMF Bz have been obtained from http://omniweb.gsfc. nasa.gov/form/dx1.html. The solar activity is recorded by the F 10.7 index. It estimates the solar activity levels by estimating solar radio flux per unit frequency corresponding to the wavelength of $10.7 \mathrm{~cm}$. If $\mathrm{F} 10.7>100$ it indicates high solar activity levels; otherwise, the solar activity is considered to be low. The symmetric disturbance of horizontal geomagnetic fields (Sym-H) is one of the new geomagnetic indices like Disturbance storm time (Dst) index for space weather. It calculates the intensity of the ring currents with a temporal resolution of one minute, whereas Dst index does so with one hour resolution. Interplanetary Electric Field (IEF Ey) and Interplanetary Magnetic Field (IMF) $\mathrm{Bz}$ 
components in Geocentric Solar Magnetospheric (GSM) coordinates are also obtained for the analysis of their direction, which are carried by the solar wind towards the earth's orbit, and corresponding ionospheric TEC variations are monitored. The positive and negative anomalies in the ionospheric TEC on regional time scale could be influenced by polarity and duration of IMF Bz and IEF Ey (Tsurutani et al. 2004, 2008). During the geomagnetic storm of October-November 2003, the enhancement in the equatorial anomaly has been attributed to southward IMF Bz (Zhao et al. 2005). The positive (enhancements) and negative (depletions) anomalies are observed in the GPS-TEC due to Prompt Penetration Electric Fields (PPEF) associated with southward IMF Bz and the northward IMF Bz, respectively (Tsurutani et al. 2008). Rapid changes in the GPS-TEC are observed during the various intense space weather events such as geomagnetic storms (Forster and Jakowski 2000; Bagiya et al. 2009; Venkata Ratnam et al. 2011; Kumar et al. 2012; Kumar and Singh 2011a, b). The solar geophysical conditions and geomagnetic disturbances show significant impact on the perturbations of ionospheric parameters of equatorial and polar regions.

\section{Method for detection of ionospheric anomalies}

Ionospheric anomalies in TEC data can be detected via the wavelet technique. Wavelet analysis is a technique that has been used to observe the minute changes during small-scale ionospheric variations. The wavelet transform allows constructing the correlation between the wavelet of each scale and the TEC data.

Continuous wavelet transform (CWT) is a technique in which the sum of all time series of ionospheric TEC data is multiplied by scaled and shifted version of the mother wavelet $(\Psi)$. With respect to the mother wavelet $\Psi$, the CWT is calculated using the equation below.

$$
W_{\psi f_{b, a}}=|a|^{-1 / 2} \int_{-\alpha}^{\alpha} f(t) \Psi\left(\frac{t-b}{a}\right) d t, f \in L^{2}(R), a, b \in R, \quad a \neq 0
$$

Here, $f(t)$ is the GPS-VTEC data considered during the period of investigation. a is the scaling parameter and $\mathrm{b}$ is a position parameter. $\Psi(\mathrm{t})$ is the mother wavelet (Morlet is chosen), and the $\mathrm{L}^{2}(\mathrm{R})$ represents the space of measurable, square-integrable functions $f(t)$ (Mallat 1989; Daubechies 1992). This technique produces wavelet coefficients as a function of scale and position. The position parameter refers the time or location of the measured TEC data, and scale parameter denotes the low and high frequency fluctuations of the ionospheric TEC data. Hence, by the projection of wavelet coefficients at different scales and time, the localisation of abnormalities in GPS-TEC features can be determined, which infer the perturbations of disturbed ionosphere attributed to the geomagnetic storm in both time and frequency domains.

The depletion in the wavelet coefficient $\left(\left|W_{\psi f f}(b, a)\right|\right)$, where the amplitude relying upon the scale ' $a$ ' is associated with uniform and dot smoothness of the Lipschitz function (Jaffard 1991; Daubechies 1992; Mallat 1999). As per Zhaffar's theorem, when 'a' declines, the amplitudes of the coefficients $\left(\left|W_{\psi f f_{b, a}}\right|\right)$ rapidly decreases to zero where the function $f(t)$ is smooth and has no nearby or local components (Daubechies 1992; Mallat 1999).Using this property of CWT, the threshold $\left(T h_{a}\right)$ value is determined to detect the 
ionospheric anomalies. The threshold $\left(T h_{a}\right)$ to detect ionospheric anomalies can be represented as (Mandrikova et al. 2015b),

$$
T h_{a}=T_{c} * S c_{a}
$$

Where, $T c$ is a threshold coefficient,

In this analysis, we have considered $\mathrm{T}_{\mathrm{c}}=2.5$ for high solar activity period (Mandrikova et al. 2015b). $\mathrm{Sc}_{\mathrm{a}}$ is the anomaly detecting parameter for scale 'a' given by,

$$
S c_{a}=\sqrt{\left(\frac{1}{\phi-1}\right) \sum_{b=1}^{\phi}\left(W_{\psi f f_{b, a}}-\bar{W}_{\psi f_{b, a}}\right)^{2}}
$$

Where, $\bar{W}_{\psi f_{b, a}}$ and $W_{\psi f_{b, a}}$ are the mean of TEC and TEC coefficients for a moving time window of length $\Phi$ of $240 \mathrm{~h}$.

The ionospheric anomalies can be detected by using the formula given by (Mandrikova et al. 2015b),

$$
P_{T h_{a}}\left(W_{\psi f_{b, a}}\right)=\left\{\begin{array}{rr}
W_{\psi f_{b, a}}, & \text { if }\left|W_{\psi f_{b, a}}-W_{\psi f_{b, a}^{m e d}}\right| \geq T h_{a} \\
0, & \text { if }\left|W_{\psi f_{b, a}}-W_{\psi f_{b, a}^{m e d}}\right|<T h_{a}
\end{array}\right.
$$

$W_{\psi f_{b, a}^{m e d}}$ is the median value of the ionospheric VTEC derived from the IRI-2012 model, and is calculated independently for each hour.

The intensity of ionospheric anomaly at time (position), $\mathrm{t}=\mathrm{b}$ is given by (Mandrikova et al. 2015b),

$$
I_{b}=\sum_{a} \frac{\left|P_{T h_{a}}\left(W_{\psi f_{b, a}}\right)\right|}{\left\|W_{\psi f_{b, a}}\right\|_{2}}
$$

Where, the calculation of norm is given by

$$
\left\|W_{\psi f_{b, a}}\right\|_{2}=\sqrt{\sum_{n_{a}}\left(P_{T h_{a}}\left(W_{\psi f_{b, a}}\right)\right)^{2}}
$$

$n_{a}$ is the length of series for scale ' $\mathrm{a}$ '. The flow chart of ionospheric anomaly detection is shown in Fig. 1.

\section{Results and discussion}

The geomagnetic storms occurred on 17 March and 29 June of the year 2013. The solar irradiation may cause sudden disturbances in the magnetosphere, attributed to rapid changes in convection currents and dramatic changes in the ionospheric electron density distributions. In the present analysis, GPS-TEC data is collected from 9-18 March 2013 and 21-30 June 2013 to detect the ionospheric anomalies during ionospheric disturbances. 


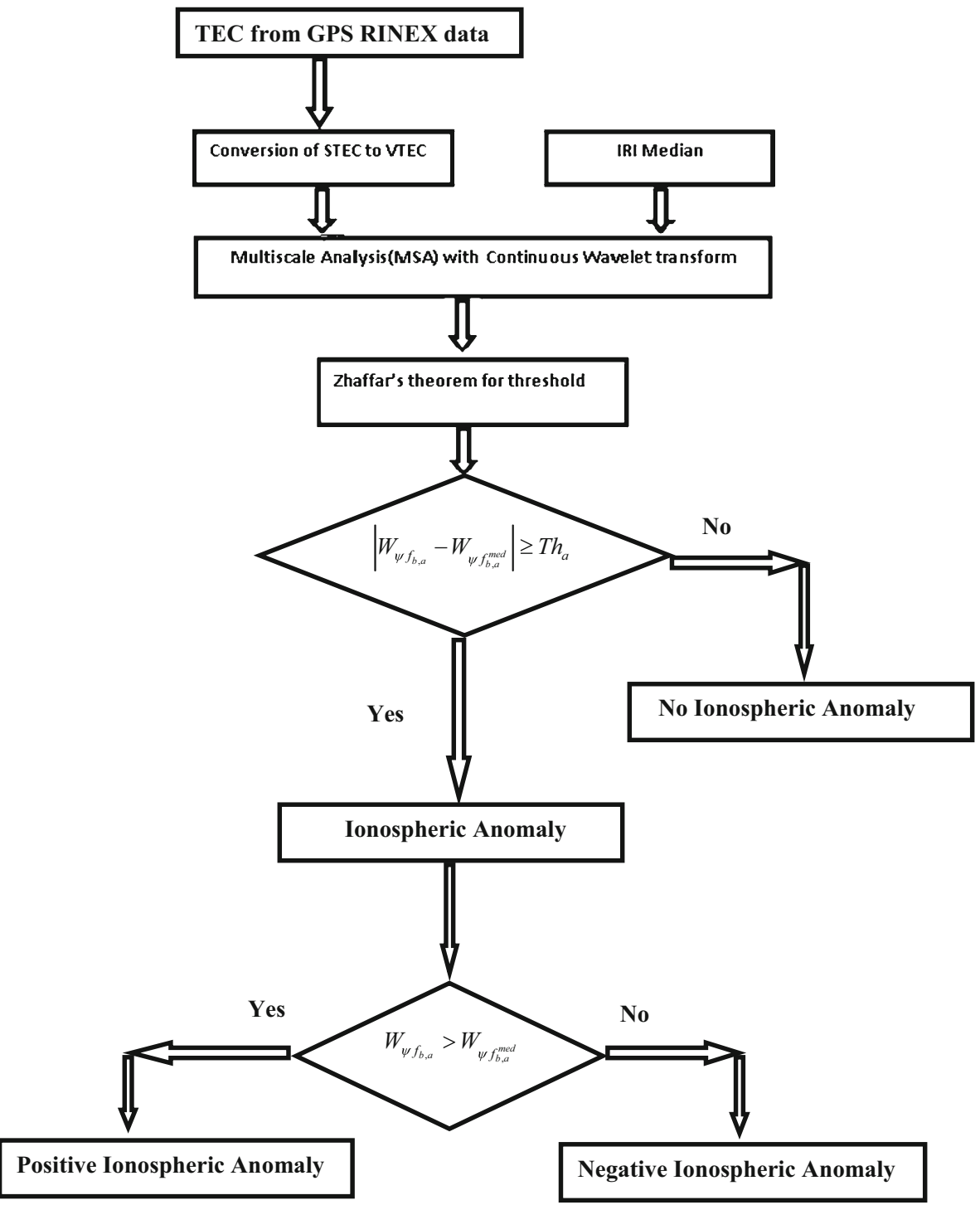

Fig. 1 The flow chart for the detection of ionospheric anomalies using GPS-TEC observations

\subsection{The geomagnetic storm on 17 March 2013}

Figure 2a-d show, respectively, variations of geomagnetic indices, F10.7 index, Interplanetary Electric Field (IEF Ey), Interplanetary Magnetic Field (IMF Bz) and the symmetric-H (Sym-H) index that have been plotted during 9-18 March 2013. Figure 2e depicts the diurnal variations of ionospheric TEC corresponding to the fluctuations in the geomagnetic indices during the same period (9-18 March 2013). Figure 2e also describes the comparison of daily VTEC variations with median values taken from the IRI-2012 model. 
The blue line indicates the GPS-VTEC values while the red line denotes the IRI-2012 derived VTEC values.

During the March 2013 storm period, the sunspot number has been recorded as 58. The panels of Fig. 2 indicate the solar and geomagnetic indices and ionospheric TEC variations. An increment in the solar radiation during 17 March 2013 is observed with the F10.7 index at a maximum value (124) from 114 solar flux units (sfu) on 9 March 2013, as shown in Fig. 2a. Figure 2b, c shows the variations of IEF Ey and IMF Bz components during the disturbed ionospheric state for the period of investigation. The fluctuations of IEF Ey and IMF Bz are mutually perpendicular. When IEF Ey is eastward, the IMF Bz is observed to be southward, and vice versa. It can be observed from Fig. 2b, c that during 9-14 March 2013, IEF Ey has fluctuated in the range of -2 to $3 \mathrm{mV} / \mathrm{m}$, whereas the IMF Bz component ranges from +5 to $-5 \mathrm{nT}$. Sym-H shows positive values on most of the occasions during 9-15 March 2013 (Fig. 2d). It is to be observed that before the storm commencement, the GPS-TEC values recorded a maximum value of 60 TECU (Fig. 2e).

A Coronal Mass Ejection (CME) from the sun erupted with a solar wind speed of $700 \mathrm{~km} / \mathrm{s}$ on 15 March 2013, reaching the earth's magnetic field at 06:00 UTC (Coordinated Universal Time) (12:00 LT) on 17 March 2013. It was a minor S1 solar radiation storm that caused a moderately strong geomagnetic storm (Jin et al. 2014; Tang et al. 2016; Raghunath and Ratnam 2016). The strong perturbations in the geomagnetic indices can be noticed during 07:00-20:00 UT (12:30-01:30 LT) during 17 March 2013. Thus, during the sudden start of magnetic storm, i.e., main phase of the storm, IEF Ey can be observed to have turned eastward from 0.23 to $9.71 \mathrm{mV} / \mathrm{m}$ during 07:00-09:00 UT (12:30-14:30 LT) h (Fig. 3); corresponding southward turning of IMF Bz (0.2-13 nT) is also observed during the daytime for long periods (Fig. 3a, b). The sudden distinctive descents in the Sym-H are also attributed to the commencement of the storm on 17 March 2013, at 07:00 UT (12:30 LT) with a record of $-4 \mathrm{nT}$ (Fig. 3c). Later, the continuous decrement in the Sym-H can be observed with a minimum value of -90 nT at 14:00 UT (19:30 LT) on 17 March 2013 and extreme minimum of $-132 \mathrm{nT}$ at 20:00 UT (01:30 LT), which can be taken as the end of the main phase. It can be observed that during the initial phase, i.e., on 16 March 2013, VTEC started to increase from 4.66 TECU at 00:00 LT, and reached 60.52 TECU at 12:00 LT. On the other hand, the geomagnetic indices values did not fluctuate much during this period (Fig. 2e). Nonetheless, during the storm day, an increment of 67.12 TECU (approximately 7 TECU more) in the VTEC values can be seen, which is indicative of positive storm effect. This enhancement in the GPS-measured ionospheric TEC might be due to the southward turning of IMF Bz associated with prompt penetration of eastward electric fields in the dayside, as shown in Figs. 2b-e and 3a-d, which causes enhancements in the EIA (Chakraborty et al. 2015; Tsurutani et al. 2004). During the main phase of the magnetic storm, ionospheric TEC data has shown large deviations from median values compared to the geomagnetic quiet days. The decrement in the F10.7 index (116 sfu), and the recovery of IEF Ey, IMF Bz and Sym-H values, restoring to the quiet day measurements, represent the immediate recovery phase of the magnetic storm on 18 March 2013 (Fig. 2a-d). Thus, during the recovery phase of the storm, the peak VTEC value observed is 64.36 TECU, which is 3 TECU less than the storm day ionosphere TEC peak value (Fig. 2e).

In order to analyse the complex structures in the ionospheric anomalies, a multiscale analysis of GPS-VTEC and VTEC derived from the IRI-2012 model has been processed with CWT, the results of which are shown in Fig. 4. The scale in Fig. 4a refers to the compressed or stretched form of the mother wavelet (Morlet) function. The magnitude of the CWT coefficients for a given scale and position is a measure of the energy at that scale and location. The multiple scales of CWT represent the intrinsic low and high frequency 

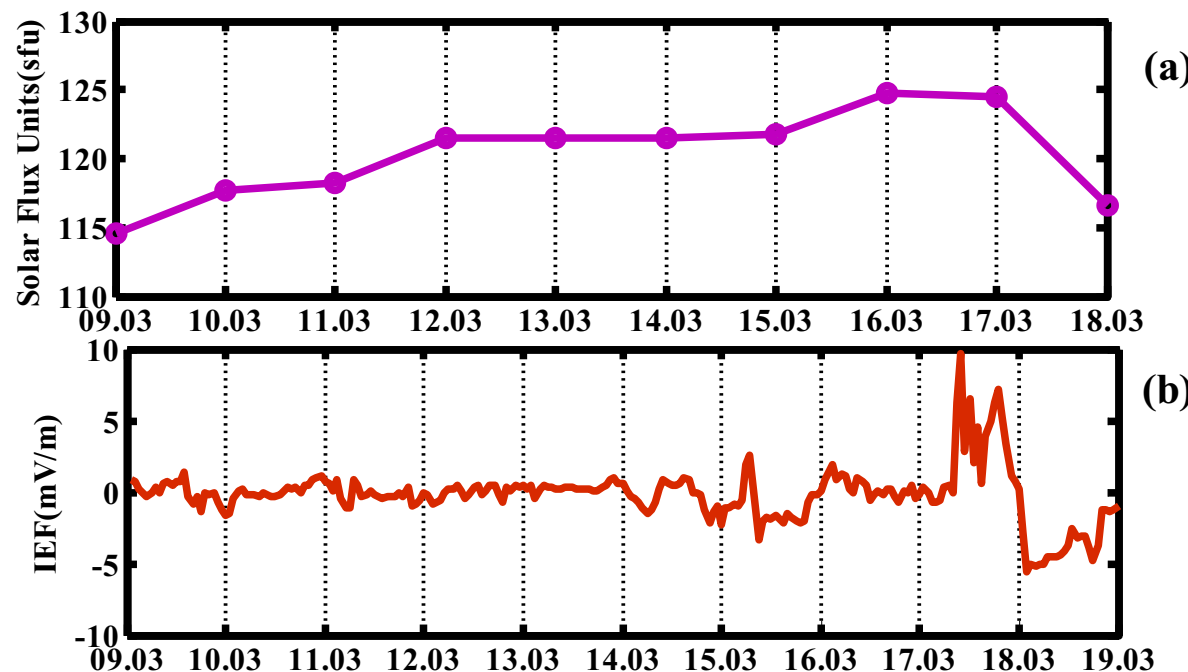

(b)
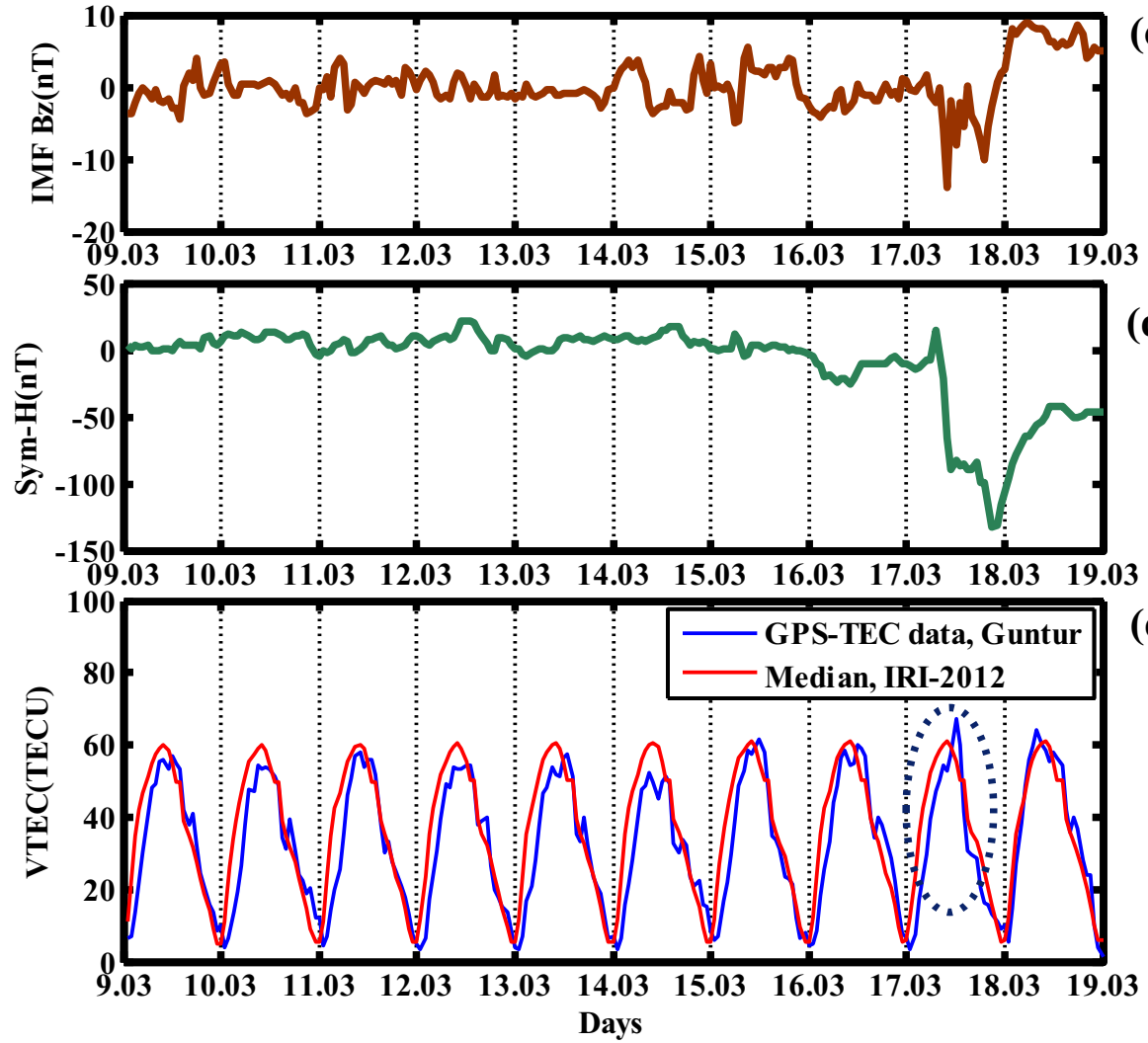

(d)

Fig. 2 Variations of geomagnetic and ionospheric data a F10.7 index, b IEF Ey, c IMF Bz d Sym-H index, e variations of GPS-VTEC and VTEC derived from the IRI-2012 model during March 2013 storm during 9-18 March 2013 over Guntur (Geographic Lat.16.37 N, Geographic Long. 80.37 E) 

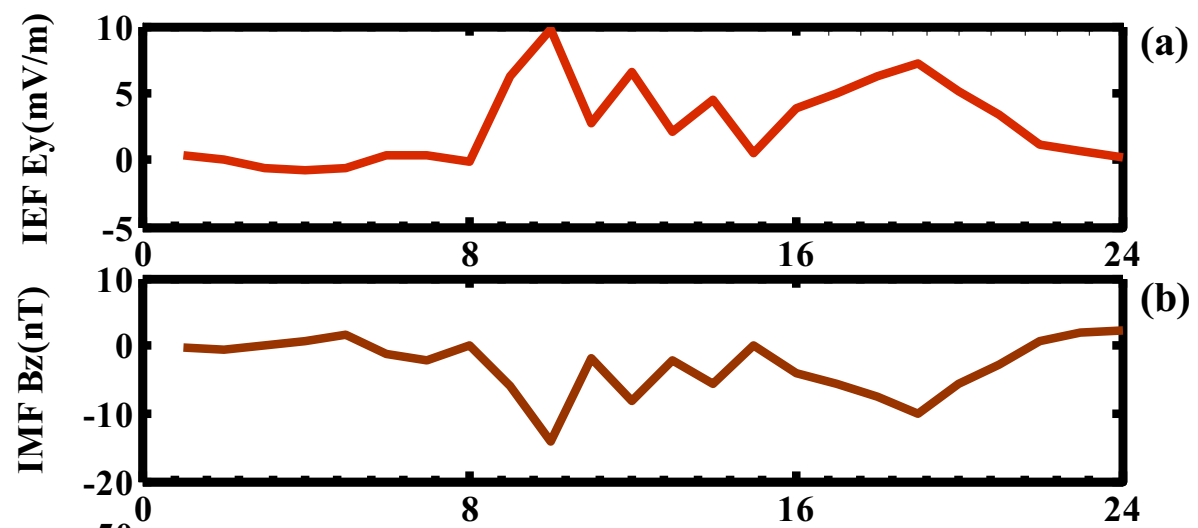

(b)

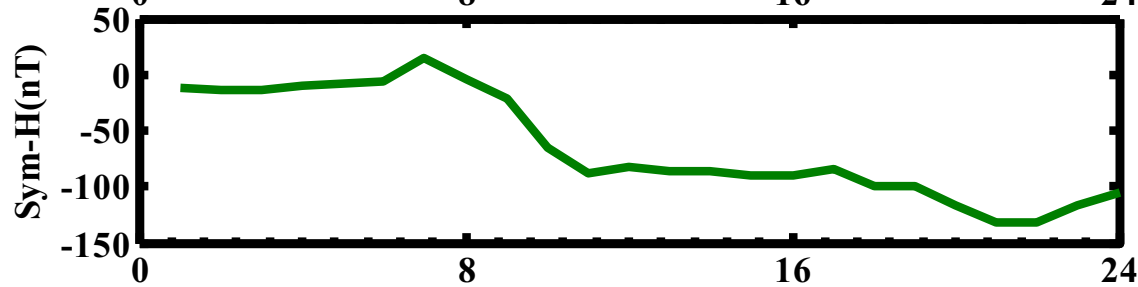

(c)

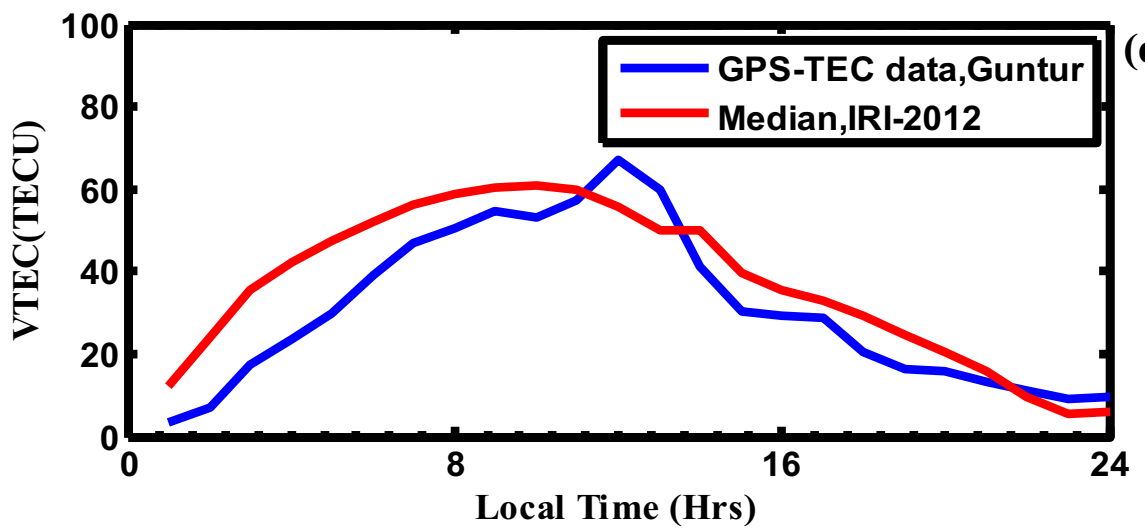

Fig. 3 The variations of geomagnetic and ionospheric data a IEF Ey, b IMF Bz, c Sym-H index, d GPSVTEC and VTEC derived from IRI-2012 model during 17 March 2013 over Guntur (Geographic Lat. $16.37^{\circ} \mathrm{N}$, Geographic Long. $80.37^{\circ} \mathrm{E}$ )

fluctuations of VTEC data during the intense storm period. Thus, the application of CWT can be used to register the local characteristics of TEC for position ' $b$ ' in scales 'a.' The presence of ionospheric anomaly at scale 'a' can be detected using the threshold function, $\mathrm{Th}_{\mathrm{a}}$. The comparison of GPS TEC data with IRI median enables the detection of ionospheric anomalies. In the present analysis, the threshold values for the detection of ionospheric anomalies have been obtained using Eq. 2, which is in the range of 0.12-1.7 for the GPS-TEC data during the March 2013 storm. Figure 4a shows the results of ionospheric anomaly detection attributed to the positive storm effect due to the March 2013 storm. The brick red colour indicates maximum energy of the coefficient at scale 8 , which has been detected on the storm day, 17 March 2013 (Fig. 4a). It is obvious that the enhancement in the electron density is due to prompt penetration electric field, which has been detected 


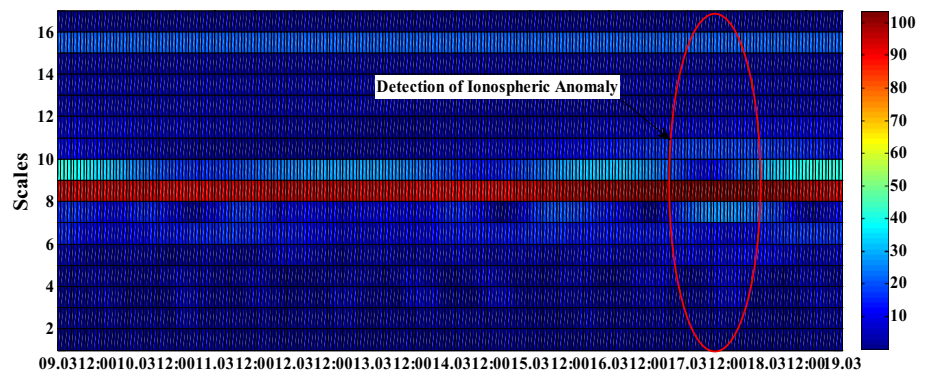

(a) Days (LT) (9-18 March 2013)

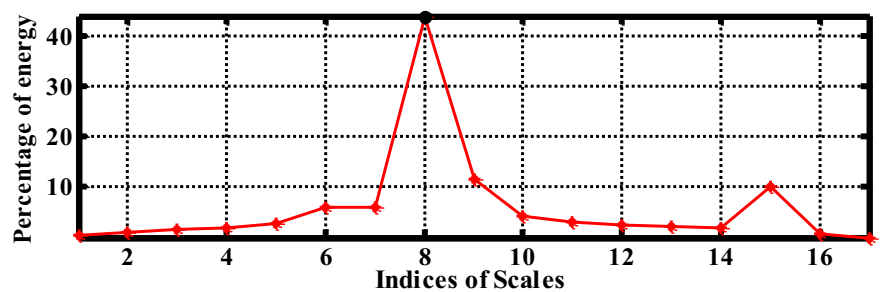

(b)

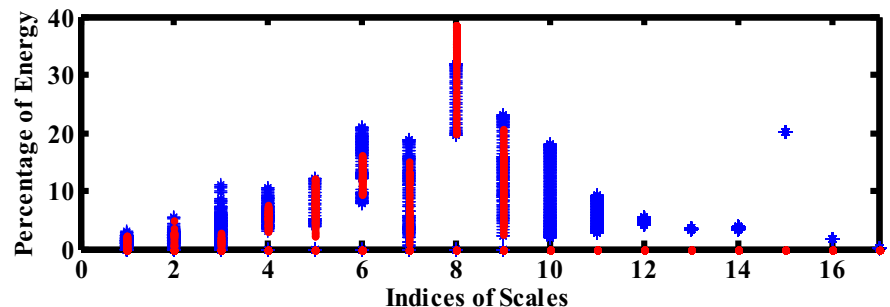

(c)

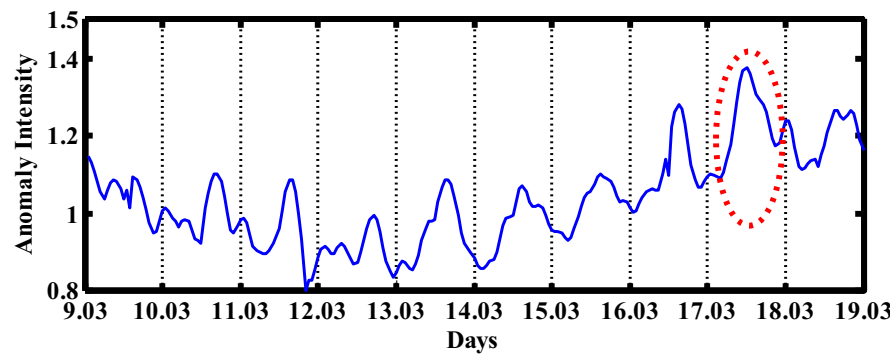

(d)
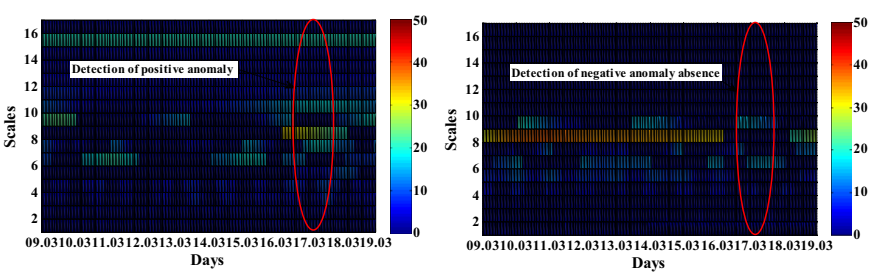

(e)

Fig. 4 Detection of ionospheric anomalies during geomagnetic disturbances for March 2013 storm (9-18 March 2013) a detection of anomalies for the threshold coefficient of Tc $=2.5$, b Percentage of energy in the GPS-TEC scales, c positive and negative anomalies representation, $\mathbf{d}$ variation in intensity of ionospheric anomalies, e the energy distribution of positive anomaly (left) and negative anomaly (right) observed in the CWT time-scale plane 
through this coloured plot with an arrow mark shown in Fig. 4a. The percentage of energy distribution of anomaly is irregular at different scales in the measured GPS- TEC during the strong geomagnetic storm (Fig. 4b). Percentage energy of more than 40 can be observed at the scale 8, as shown in Fig. 4b). Figure 4a, b demonstrates the ionospheric positive anomaly (increment in the electron density) at the 8th scale during the storm day (17 March 2013) compared to the pre- and post-storm days. The reason for the maximum storage of energy at 8th scale is due to the detection of ionospheric anomalies using the ionospheric TEC data and the median values. It can also be noticed in Fig. $4 \mathrm{~b}$ that the percentage of energy levels rises from the lower scales to the 8th scale and then resumes its lower scale. When the coefficients of the GPS-TEC data exceed their median coefficients by the threshold $\left(\mathrm{Th}_{\mathrm{a}}\right)$, as given in Eq. 4, it is characterised by positive anomaly, indicating the increment in the distribution of electron density compared to the background level. In contrast, negative anomaly refers to the depletion in the TEC values, which is described as the median coefficients exceeding the coefficients of GPS-TEC data by the same threshold $\left(\mathrm{Th}_{\mathrm{a}}\right)$. The scale-wise positive (red) and negative anomalies (blue) associated with ionospheric TEC during the March 2013 storm period has been shown in Fig. 4c, which illustrates the localised existence of ionospheric anomalies.

Figure $4 \mathrm{~d}$ shows the variations in the intensity of VTEC anomalies, which have been detected using Eq. 5 during the March 2013 storm (9-18 March 2013). However, the intensity has different peaks during quiet days; the linear relationship between the geomagnetic indices and ionospheric anomaly intensity response can be analysed from Figs. 2 and 4. The day-to-day irregularities in low-latitude ionospheric TEC are significant due to equatorial ionisation anomaly (EIA) and equatorial electrojet (EEJ) (Huang et al. 1989; Rastogi and Klobuchar 1990). Moreover, as shown in Fig. 2, the fluctuations in the peaks of anomaly intensity during quiet days may be due to the variations in solar radiation flux and strength of geomagnetic field (Fig. 4d). It can be observed that the enhancement in anomaly intensity (1.4) during both day and night times during the storm day (17 March 2013) corresponded to the strong magnetic storm (Fig. 4d). It can also be seen that a sudden increase in anomaly intensity on the storm day and immediate decrease in the anomaly intensity level on the next day correspond to the significant detection of ionospheric anomalies. The enhancement of anomaly intensity on the March storm day (17 March 2013) may be due to the uplifted plasma associated with ExB drifts driven by Prompt Penetration Electric Fields (PPEF) (Tsurutani et al. 2004; Rastogi and Klobuchar 1990). The reduced anomaly intensity can be noticed during the post-storm day (Fig. 4d), which may be attributed to the depletion in the solar flux; also, it may be noticed that Sym$\mathrm{H}$ values begin to regain their quiet time value during the recovery phase of the storm (Fig. 2). Figure 4e illustrates the energy distribution for ionospheric positive and negative anomalies during the March storm period (9-18 March 2013). The presence of small-scale positive anomaly and absence of negative anomaly have been identified using Eq. 4 during the main phase of March 2013 storm, as shown in Fig. 4e. It is observed that the implemented method has apparently detected the ionospheric anomaly (positive storm effect), caused by adverse geo-magnetic and solar activity, during the main phase of the storm.

\subsection{The geomagnetic storm on 29 June 2013}

On 29 June 2013, the earth's geomagnetic field was disturbed by a high-speed stream of CME from the sun. The sunspot number during this June 2013 storm period was 52.5. During 21-30 June 2013, the variations in ionospheric TEC data as depicted by the geomagnetic indices F10.7 index, Interplanetary Electric Field (IEF Ey), Interplanetary 
Magnetic Field (IMF Bz) and the symmetric-H (Sym-H) index have been plotted as shown in Fig. 5. Figure 5a describes the high solar activity levels indicated by the F 10.7 index. The rapid variations in the direction of IEF Ey and IMF Bz components during 21-30 June 2013 can be observed from the Fig. 5b, c. The consistent and rapid variations in the Sym-H index with IMF Bz and IEF Ey fluctuations are shown in Fig. 5d. The response of observed ionospheric TEC due to these geomagnetic indices has been plotted in Fig. 5e. The variability of low-latitude ionosphere is driven by the zonal electric fields during the geomagnetic quiet time and the storm-induced electric fields may cause intense irregularities by producing substantial ring currents. During the period of investigation for the June 2013 storm, it has been observed that there is a rapid decrement ( $35 \mathrm{sfu}$ ) during the storm day 29 June 2013 (105) in the F 10.7 index, compared to the value of 140 sfu on 21 June 2013.

During the initial phase of the storm, westward turn of the IEF Ey (change from 1.6 to $3.6 \mathrm{mV} / \mathrm{m}$ ) and northward turn of IMF Bz (increased from -3.9 to $8.8 \mathrm{nT}$ ) can be observed in the early hours 00:00 to 06:00 UT (05:30 to11:30 LT); immediately afterwards at 11:30 LT, the IEF Ey orients eastward (increased from -3.6 to $4.5 \mathrm{mV} / \mathrm{m}$ ) while IMF Bz can be observed to have turned southward (decreased from 8.8 to $-12 \mathrm{nT}$ ) during the remaining hours (Fig. 6a, b). However, steady descents can be observed in the Sym-H index values, reaching a minimum excursion of $-22 \mathrm{nT}$ at 12:00 UT (17:30 LT) during 28 June 2013 (Fig. 6c). The corresponding background VTEC values over the Guntur station have been noted at 9 TECU at 00:00 LT, reaching a maximum value of 47.74 TECU at 12:00 LT (Fig. 6d). During the main phase of the storm, i.e., 29 June 2013, the consistent variations in the Sym-H index with IMF Bz and IEF Ey fluctuations have been shown in Fig. 6a-c. It can be noticed that the IEF Ey turned eastward (raised from 2.61 to $4.34 \mathrm{mV} / \mathrm{m}$ ) between 00:30 and 08:30 LT, and is westward (decreased from 4.12 to $3.87 \mathrm{mV} / \mathrm{m}$ ) between 05:00 and 07:00 UT (10:30-12:30 LT) on 29 June 2013 (Fig. 6a). The commencement of the storm on 29 June 2013 is marked at around 07:00 UT (12:30 LT) with a minimum trip of Sym-H index at $-98 \mathrm{nT}$ (Fig. 6c). The westward IEF Ey and the northward IMF Bz (decreased from -11.2 to $-9.6 \mathrm{nT}$ ) may be observed during daytime (10:30-12:30 LT) (Fig. 6b), causing the Disturbance Dynamo Electric Fields (DDEF) results in reduced ExB drifts and TEC (Chakraborty et al. 2015; Mannucci et al. 2009). This negative effect of the June storm has shown a depletion of approximately 10 TECU in the peak TEC values (36.59 TECU) compared to the peak values of the pre-storm day over the Guntur station during the peak hours 10:30-12:30 LT on 29 June 2013 (Fig. 6d). Later, at 07:00 UT (12:30 LT), the Sym-H index begins to get restored to the quiet condition, recovering completely on 30 June 2013 (Fig. 6c). The enhancement in the VTEC values up to 53.8 TECU during the recovery phase of the storm on 30 June 2013 can also be observed. Thus, a large depletion in TEC values can be observed during the main phase of the storm (29 June 2013), to the value of 10 TECU (negative storm effect) compared to the pre-storm day; also, an enhancement of 17 TECU during the recovery phase can be observed due to the strong electrodynamics associated with IEF Ey and IMF Bz fluctuations, as shown in Fig. 6a-d.

The detection of ionospheric anomalies during the negative phase effect of the June 2013 storm has been shown in Fig. 7. The energy of ionospheric anomalies varies proportionately with the perturbation of the geomagnetic indices. The ionospheric anomalies are characterised using the threshold $\left(\mathrm{Th}_{\mathrm{a}}\right)$ values calculated from Eq. 2, which lies between 0.14 and 1.6. Figure 7 a shows the multiscale analysis of ionospheric anomalies during the period of June 2013 storm (21-30 June 2013). The time-scale representation of GPS-VTEC has been plotted in Fig. 7a. Negative storm effect, i.e., the depletion of energy levels in all the scales on the storm day (29 June 2013) can be observed during the period 

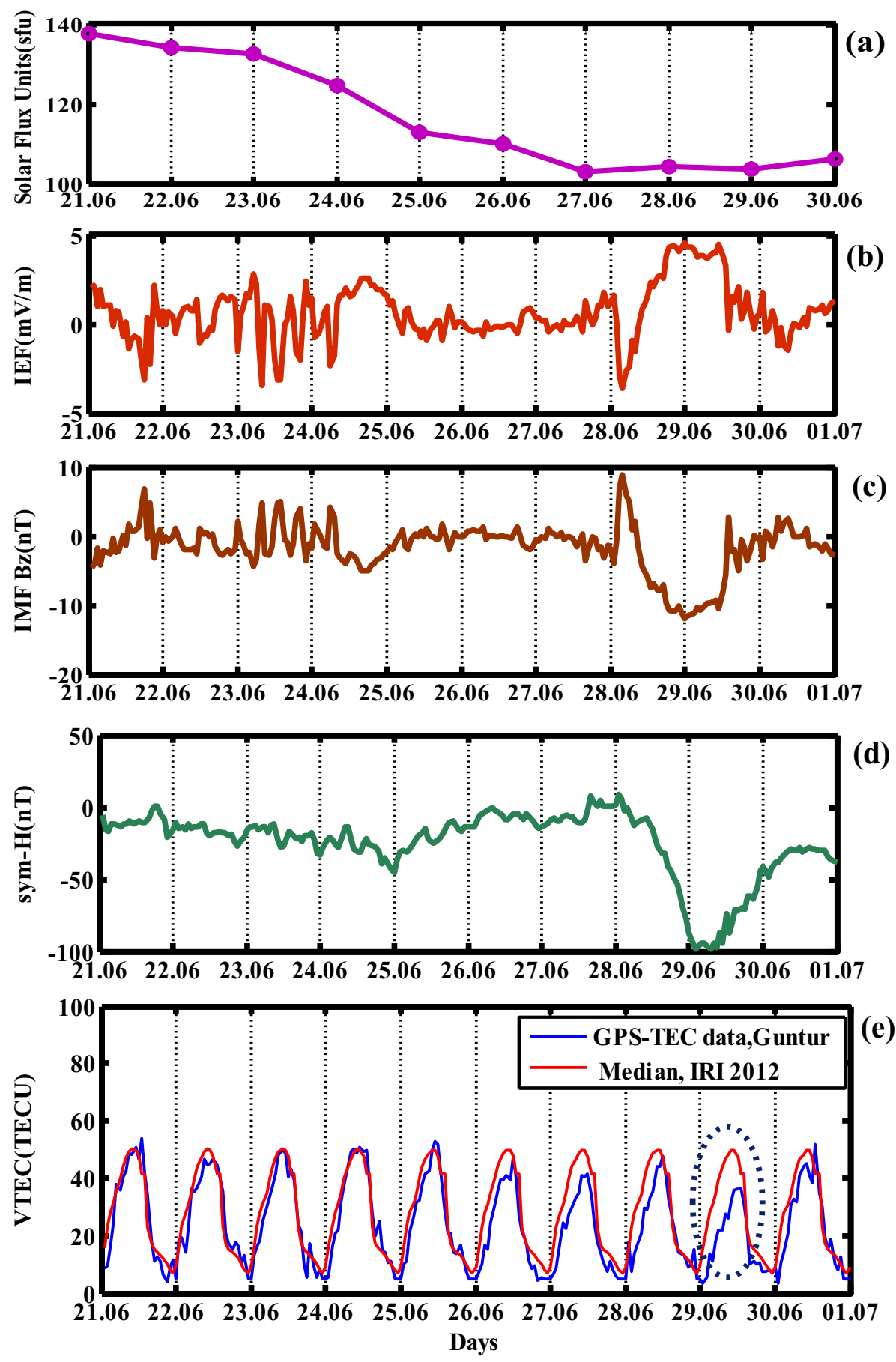

Fig. 5 Variations in the geomagnetic indices a F10.7 index, b IEF Ey, c IMF Bz, d Sym-H index, e the variations of GPS-VTEC and VTEC derived from the IRI-2012 model during June 2013 storm. The plot spans 21-30 June 2013 over Guntur (Geographic Lat.16.37 N, Geographic Long. 80.37 ${ }^{\circ} \mathrm{E}$ ) 


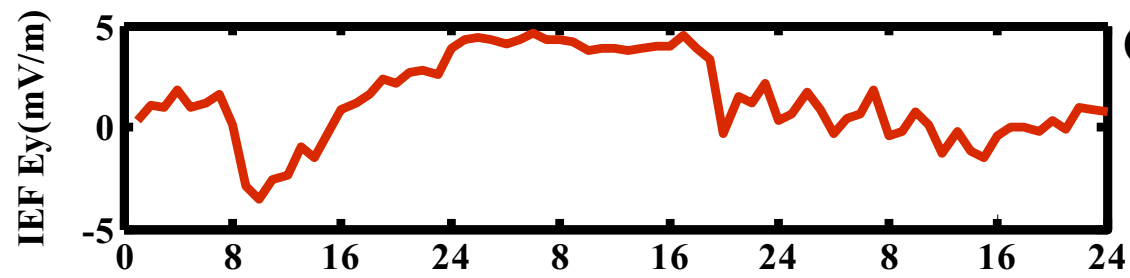

(a)

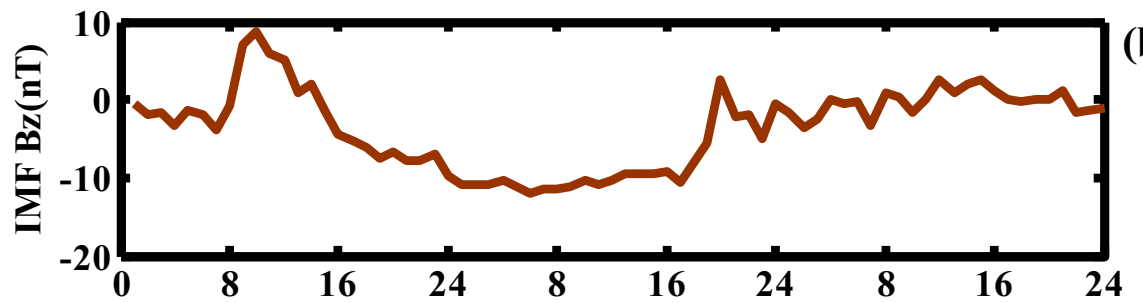

(b)
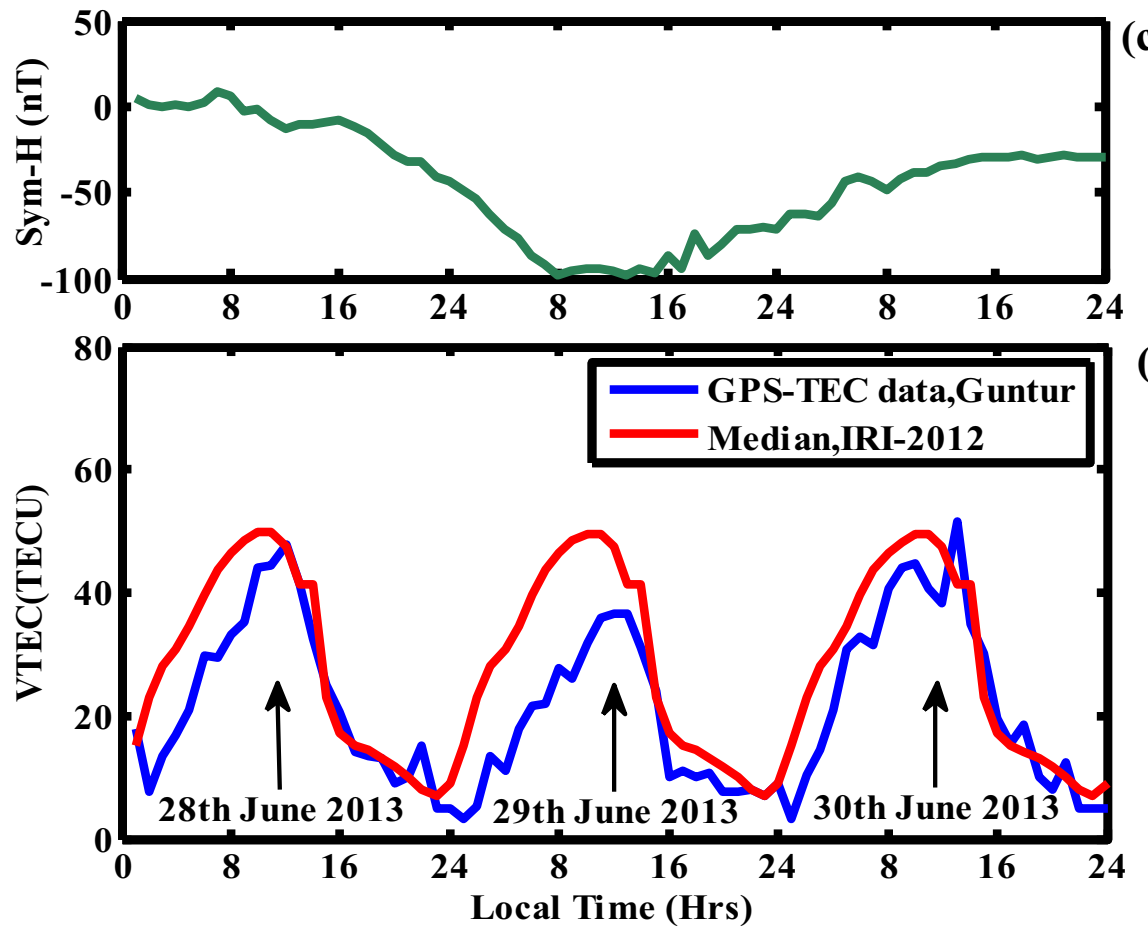

(d)

Fig. 6 The variations of geomagnetic and ionospheric data a IEF Ey, b IMF Bz, c Sym-H index, d GPSVTEC and VTEC derived from IRI-2012 model during 28-30 June 2013 over Guntur (Geographic Lat. $16.37^{\circ} \mathrm{N}$, Geographic Long. $80.37^{\circ} \mathrm{E}$ )

10:30-12:30 LT, as marked in Fig. 7a. It is apparent from the results that the multiscale analysis model is able to detect the reduction in the abnormal VTEC variations during magnetic storm day on 29 June 2013. The scale-wise percentage of energy stored for ionospheric TEC during the June 2013 storm is shown in Fig. 7b. The positive (red) and negative (blue) anomalies in different scales are represented in Fig. 7c, using Eq. 4. Variations in the intensity of ionospheric anomalies are demonstrated in Fig. 7d during the 


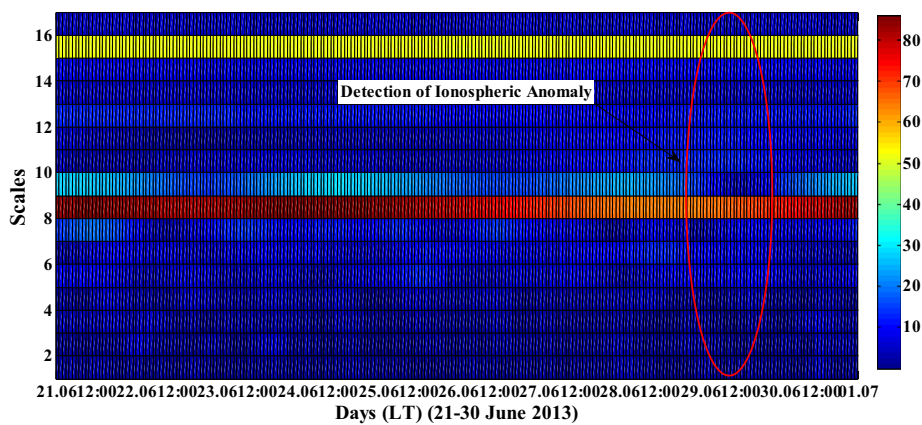

(a)

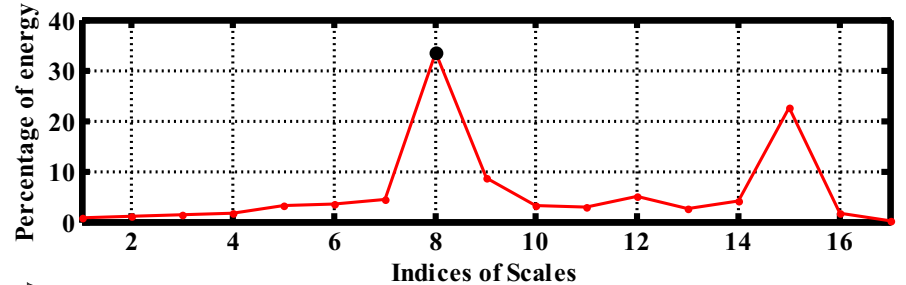

(b)

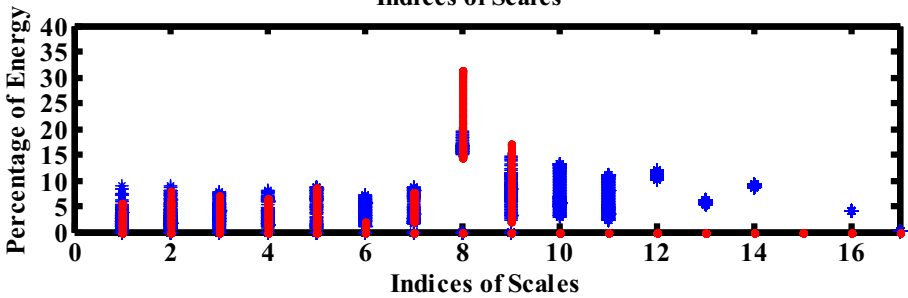

(c)

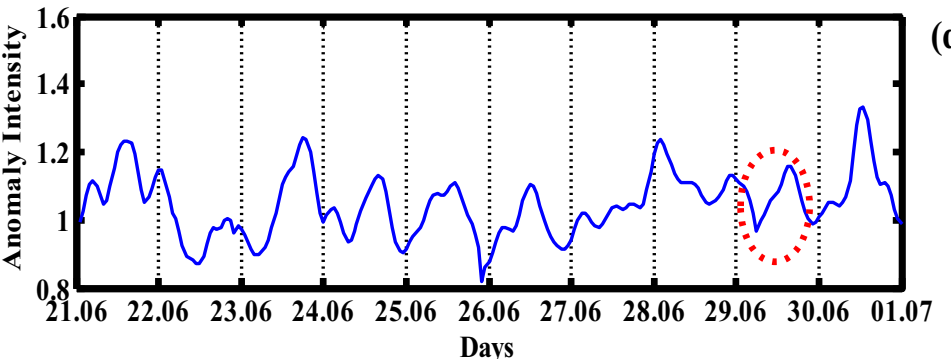

(d)
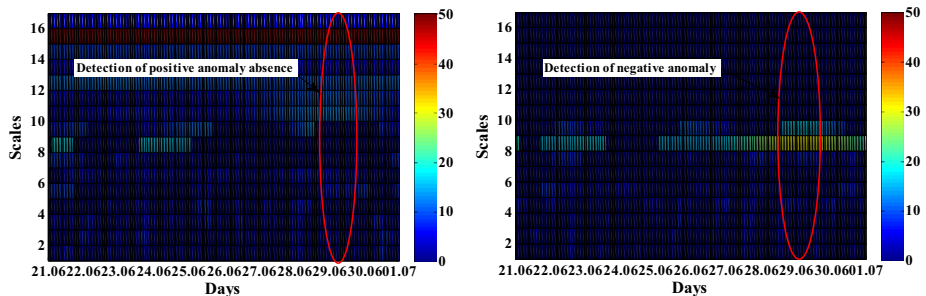

(e)

Fig. 7 Detection of ionospheric anomalies during geomagnetic disturbances for the June 2013 storm (21-30 June 2013) a detection of anomalies for the threshold coefficient of $\mathrm{Tc}=2.5$, b Scale wise percentage of energy in the GPS-TEC, $\mathbf{c}$ positive and negative anomalies representation $\mathbf{d}$ intensity variation of ionospheric anomalies, e the energy distribution of positive anomaly (left) and negative anomaly (right) observed in the CWT time-scale plane 


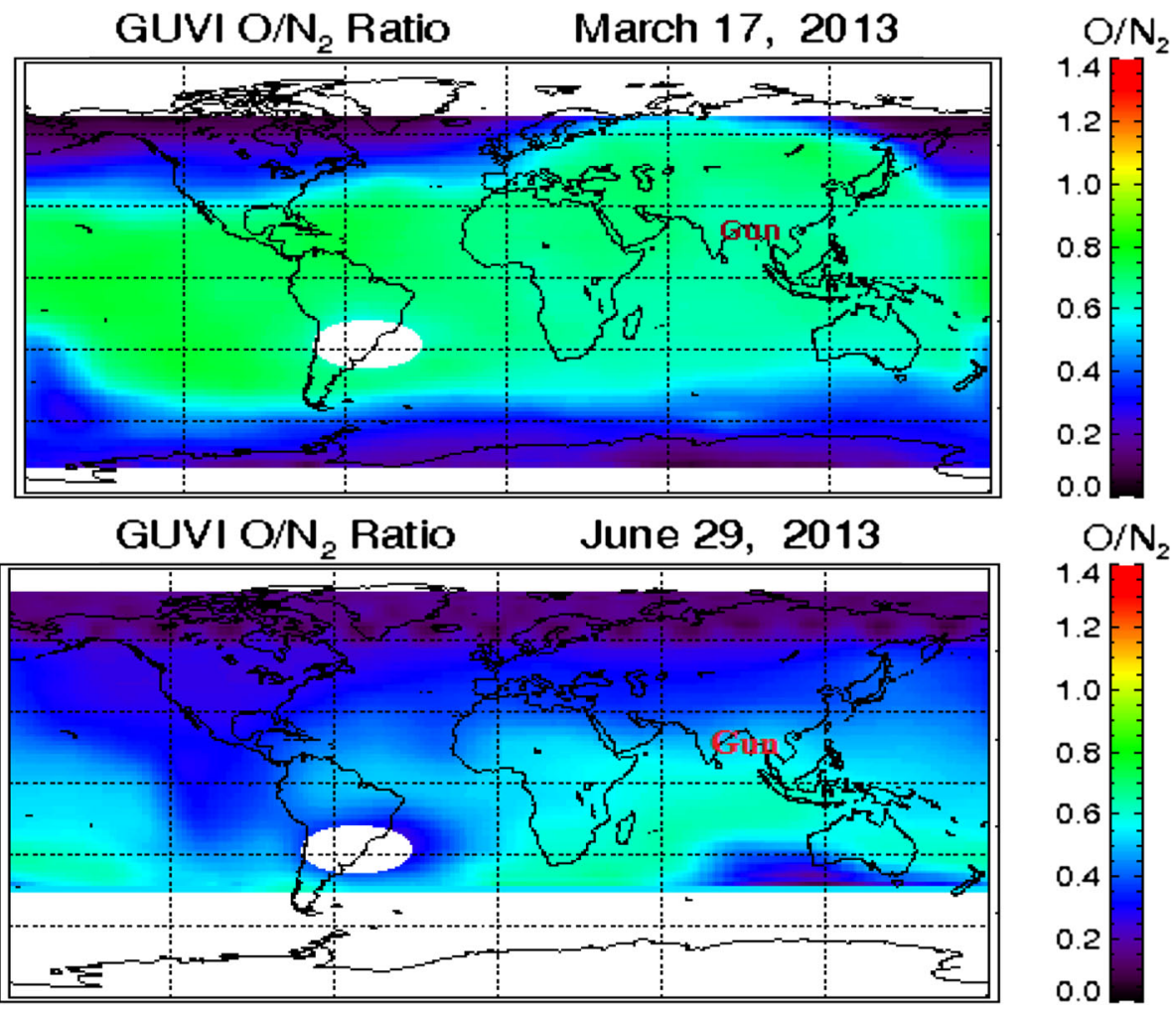

Fig. 8 The GUVI images of the thermospheric O/N 2 ratio on March storm day (17 March 2013) and June storm day (29 June 2013)

period of 21-30 June 2013. Rapid variations in the intensity of ionospheric anomalies can be observed even during the geomagnetic quiet time due to perturbations in the space weather events. During pre-storm and post-storm days, high intensity values can be observed, accompanied by a weak geomagnetic field and increment in the solar radiation. It is observed that the depletion in the anomaly intensity (1.1) during storm day is remarkable, as shown in Fig. 7d, which is due to the depletion in the ExB drifts caused by disturbed dynamo electric fields. During the storm day 29 June 2013, the depletion in the presence of ionospheric positive anomalies and enhancements in the negative anomalies energy have been illustrated in Fig. 7e using Eq. 4. Thus, the negative anomaly intensity represents decrement in the electron density gradients due to the intense geomagnetic activity of the June 2013 storm, which is quite distinct from the enhancement in electron density during the March 2013 storm (Figs. 4 and 7).

Further, in order to evaluate the positive effect (enhancement in VTEC) during the March 2013 storm and negative storm effect (depletion in VTEC) during the June 2013 storm over the EIA region, Guntur, the neutral atmospheric composition $\left(\mathrm{O} / \mathrm{N}_{2}\right)$ ratio has been obtained from TIMED/GUVI (Global Ultraviolet Imager, onboard the TIMED satellite) accessed at http://guvi.jhuapl.edu/site/. The ionospheric electron density is strongly influenced by a neutral composition in the thermosphere. The production rate of electrons depends on the concentration of atomic oxygen, $\mathrm{O}$, whereas the concentration of the molecular species $\mathrm{N}_{2}$ controls their loss rate. Thus, the oxygen-rich/nitrogen-depleted 
thermospheric air causes enhancement in the ionospheric electron density and nitrogenrich/oxygen-depleted air causes depletion in the electron density of ionosphere (Zhang et al. 2004). It is evident from Fig. 8 that during the March 2013 storm, higher $\mathrm{O} / \mathrm{N}_{2}$ ratio has been recorded compared to the June 2013 storm. This observation of $\mathrm{O} / \mathrm{N}_{2}$ ratio is in agreement with the GPS-TEC observed during the commencements of March and June 2013 storms over Guntur station (Figs. 2, 5 and 8). Thus, the effect of the magnetic storm depends on the local period of their occurrence. A similar case of magnetic storm impact has already been reported (Chakraborty et al. 2015; Pedatella et al. 2009; Bagiya et al. 2009; Kumar et al. 2012). Moreover, it is confirmed that the perturbations in the ionospheric TEC are not only driven by solar radiation and geomagnetic field but also by the composition changes in the thermospheric $\mathrm{O} / \mathrm{N}_{2}$ ratio. Nonetheless, the multiscale analysis carried out in this paper using the CWT has given efficient results in detecting the smallscale ionospheric anomalies (Figs. 4e and 7e) during the intense geomagnetic disturbances that occurred during the maximum activity of 24th solar cycle, 2013. Thus, the outcome of this analysis would be useful for understanding the distribution of anomalies in the nonlinear ionospheric electron density during the sudden shock caused by geomagnetic storms. However, the computation process of CWT requires more time due to its redundant information (i.e., each coefficient has highly correlated neighboring values) of the signals (Jauregui 2014; Goswami and Chan 2011; Weeks 2010). Moreover, the selection of mother-wavelet function plays a crucial role in the application of CWT technique for the detection of ionospheric anomalies.

\section{Conclusion}

The present paper highlights the determination and detection of localised ionospheric anomalies during two intense geomagnetic storms that occurred during the 24th solar maximum year 2013 over the Indian EIA region, Guntur. The localised characteristics of ionospheric anomalies are analysed through the implementation of Continuous wavelet transform (CWT). Significant anomaly intensities have been detected through threshold values during the March 2013 storm (high degree) as well as the June 2013 storm (low degree), which are confirmed by observed GPS-TEC values and $\mathrm{O} / \mathrm{N}_{2}$ ratio during the magnetic storm period over Guntur station. However, the impact of space weather events on the perturbations of ionosphere differs corresponding to their period of commencement and geographical location. Thus, the detection of ionospheric anomaly is useful for improving the performance of satellite-based communication and navigation systems during adverse space weather conditions.

Acknowledgement Dr. D. Venkata Ratnam would like to express his thanks to the Department of Science and Technology, New Delhi, India for funding this research through SR/FST/ESI-130/2013(C) FIST program. The work of Dr. D. Venkata Ratnam is supported through F. 301/2013(SAII)/RA201416GEANP5585. Authors are very much thankful to both the referees for giving valuable critical and precise comments/suggestions to improve the quality of this manuscript.

\section{References}

Aarons J, Basu S (1994) Ionospheric amplitude and phase fluctuations at the GPS frequencies. ION GPS-94, Salt Lake City, pp 1569-1578 
Bagiya MS, Joshi H, Iyer K, Aggarwal M, Ravindran S, Pathan B (2009) TEC variations during low solar activity period (2005-2007) near the equatorial ionospheric anomaly crest region in India. Ann Geophys 27:1047-1057

Bilitza D (2001) International reference ionosphere 2000. Radio Sci 36:261-275

Bilitza D et al (2014) The international reference ionosphere 2012-a model of international collaboration. J Space Weather Space Clim 4:A07

Buonsanto MJ (1999) Ionospheric storms-a review. Space Sci Rev 88:563-601

Chakraborty M, Kumar S, De BK, Guha A (2015) Effects of geomagnetic storm on low latitude ionospheric total electron content: a case study from Indian sector. J Earth Syst Sci 124:1115-1126

Cherniak I, Krankowski A, Zakharenkova I (2014) Observation of the ionospheric irregularities over the Northern Hemisphere: methodology and service. Radio Sci 49(8):653-662

Chui CK (1992) In: Chui CK (ed) Wavelets: a tutorial in theory and applications wavelet analysis and its applications. Academic Press, San Diego, p 1

Dashora N, Pandey R (2007) Variations in the total electron content near the crest of the equatorial ionization anomaly during the November 2004 geomagnetic storm. Earth Planets Space 59:127-131

Daubechies I (1992) Ten lectures on wavelets 61. SIAM,

Forster M, Jakowski N (2000) Geomagnetic storm effects on the topside ionosphere and plasmasphere: a compact tutorial and new results. Surv Geophys 21:47-87

Goswami JC, Chan AK (2011) Fundamentals of wavelets: theory, algorithms, and applications, vol 233. Wiley, Hoboken

Huang YN, Cheng K, Chen SW (1989) On the equatorial anomaly of the ionospheric total electron content near the northern anomaly crest region. J Geophys Res 94(A10):13515-13525

Hunsucker RD, Hargreaves JK (2007) The high-latitude ionosphere and its effects on radio propagation. Cambridge University Press, Cambridge

Jacobsen KS (2014) The impact of different sampling rates and calculation time intervals on ROTI values. J Space Weather Space Clim 4:A33

Jaffard S (1991) Pointwise smoothness, two-microlocalization and wavelet coefficients. Publ Mat 35:155-168

Jain A, Tiwari S, Jain S, Gwal A (2010) TEC response during severe geomagnetic storms near the crest of equatorial ionization anomaly. Indian J Radio Space Phys 39:11-24

Jakowski N, Stankov SM, Klaehn D (2005) Operational space weather service for GNSS precise positioning. Ann Geophys 23(9):3071-3079

Jauregui JC (2014) Parameter identification and monitoring of mechanical systems under nonlinear vibration. Elsevier, Amsterdam

Jin R, Jin S, Tao X (2014) Ionospheric anomalies during the March 2013 geomagnetic storm from BeiDou navigation satellite system (BDS) observations. China satellite navigation conference (CSNC) proceedings, I edn. Springer, Berlin, pp 97-104

Kelley MC (1985) Recent results and outstanding problems of equatorial spread-F. J Atmos Sol Terr Phys 47(8):745-752

Kumar S, Singh A (2011a) GPS derived ionospheric TEC response to geomagnetic storm on 24 August 2005 at Indian low latitude stations. Adv Space Res 47:710-717

Kumar S, Singh A (2011b) Storm time response of GPS-derived total electron content (TEC) during low solar active period at Indian low latitude station Varanasi. Astrophys Space Sci 331:447-458

Kumar S, Priyadarshi S, Krishna SG, Singh A (2012) GPS-TEC variations during low solar activity period (2007-2009) at Indian low latitude stations. Astrophys Space Sci 339:165-178

Langley RB (1996) Propagation of the GPS signals. GPS for Geodesy. Springer, Berlin, pp 103-140

Malik R, Sarkar S, Mukherjee S, Gwal A (2010) Study of ionospheric variability during geomagnetic storms. J Indian Geophys Union 14:47-56

Mallat S (1989) A theory for multiresolution signal decomposition: the wavelet representation. IEEE Trans Pattern Anal Mach Intell 11(7):674-693

Mallat S (1999) A wavelet tour of signal processing. Academic press, Cambridge

Mandrikova O, Bogdanov V (2007) Multistructural models of geophysical signals. In: Proceding 8th international conference on pattern recognition and image analysis: new information technologies (PRIA-8-2007). pp 8-12

Mandrikova O, Glushkova N, Zhivet'ev I (2014) Modeling and analysis of ionospheric parameters by a combination of wavelet transform and autoregression models. Geomagn Aeron 54:593-600

Mandrikova O, Glushkova N, Polozov YA (2015a) Simulation and analysis of time variations in ionospheric parameters on the basis of wavelet transform and multicomponent models. Pattern Recognit Image Anal 25:470-480 
Mandrikova OV, Fetisova NV, Polozov YA, Solovev IS, Kupriyanov MS (2015b) Method for modeling of the components of ionospheric parameter time variations and detection of anomalies in the ionosphere. Earth Planets Space 67:1-16

Mannucci AJ, Tsurutani BT, Kelley MC, Iijima BA, Komjathy A (2009) Local time dependence of the prompt ionospheric response for the 7, 9, and 10 November 2004 superstorms. J Geophys Res 114:A10308. doi:10.1029/2009JA014043

Manucci AJ, Wilson BD, Edwards CD (1993) A new method for monitoring the Earth's ionospheric total electron content using the GPS global network. ION GPS-93, Salt Lake City, pp 1323-1332

Mukherjee S, Sarkar S, Purohit P, Gwal A (2010) Seasonal variation of total electron content at crest of equatorial anomaly station during low solar activity conditions. Adv Space Res 46:291-295

Pedatella NM, Lei J, Larson KM, Forbes JM (2009) Observations of the ionospheric response to the 15 December 2006 geomagnetic storm: Long-duration positive storm effect. J Geophys Res 114:A12

Raghunath S, Ratnam DV (2015) Detection of low-latitude ionospheric irregularities from GNSS observations. IEEE J Sel Top Appl Earth Obs Remote Sens 8:5171-5176

Raghunath S, Ratnam DV (2016) Ionospheric Spatial Gradient Detector Based on GLRT Using GNSS Observations. IEEE Geosci Remote Sens Lett 13:875-879

Rama Rao P, Gopi Krishna S, Vara Prasad J, Prasad S, Prasad D, Niranjan K (2009) Geomagnetic storm effects on GPS based navigation. Annales Geophysicae, vol 5. Copernicus GmbH, Göttingen, pp 2101-2110

Rao PR, Krishna SG, Niranjan K, Prasad D (2006a) Temporal and spatial variations in TEC using simultaneous measurements from the Indian GPS network of receivers during the low solar activity period of 2004-2005. Ann Geophys 12:3279-3292

Rao PR, Niranjan K, Prasad D, Krishna SG, Uma G (2006b) On the validity of the ionospheric pierce point (IPP) altitude of $350 \mathrm{~km}$ in the Indian equatorial and low-latitude sector. Ann Geophys 8:2159-2168

Rastogi R, Klobuchar J (1990) Ionospheric electron content within the equatorial F 2 layer anomaly belt. J Geophys Res 95:19045-19052

Rees MH (1989) Physics and chemistry of the upper atmosphere, vol 1. Cambridge University Press, Cambridge

Rishbeth H, Mendillo M (2001) Patterns of F2-layer variability. J Atmos Sol Terr Phys 63:1661-1680

Sarma A, Ratnam DV, Reddy DK (2009) Modelling of low-latitude ionosphere using modified planar fit method for GAGAN. IET Radar Sonar Navig 3:609

Sastri J, Abdu M, Batista I, Sobral J (1997) Onset conditions of equatorial (range) spread F at Fortaleza, Brazil, during the June solstice. J Geophys Res 102:24013-24021

Tang J, Yao Y, Kong J, Zhang L (2016) Large-scale traveling ionospheric disturbances using ionospheric imaging at storm time: a case study on 17 March 2013. J Atmos Sol Terr Phys 145:12-20

Tsurutani B et al (2004) Global dayside ionospheric uplift and enhancement associated with interplanetary electric fields. J Geophys Res 109:A8

Tsurutani B et al (2008) Prompt penetration electric fields (PPEFs) and their ionospheric effects during the great magnetic storm of 30-31 October 2003. J Geophys Res 113:A5

Venkata Ratnam D, Sarma A, Satya Srinivas V, Sreelatha P (2011) Performance evaluation of selected ionospheric delay models during geomagnetic storm conditions in low-latitude region. Radio Sci 46:3

Vickrey JF, Kelley MC (1983) Irregularities and instabilities in the auroral F region. High-latitude space plasma physics. Springer, New York, pp 95-113

Wanninger L (1992) Monitoring total ionospheric electron content and ionospheric irregularities with GPS In: Proceeding of the symposium on refraction of transatmospheric Signals, Den Haag, Netherlands Geodetic Commission, Publications in Geodesy, Vol. 36 pp 141-146

Weeks M (2010) Digital signal processing using MATLAB \& wavelets. Jones \& Bartlett Learning, Burlington

Yeh KC, Liu C-H (1982) Radio wave scintillations in the ionosphere. Proc IEEE 70:324-360

Zhang Y et al (2004) O/N2 changes during 1-4 October 2002 storms: IMAGE SI-13 and TIMED/GUVI observations. J Geophys Res 109:A10

Zhang H, Wang J, Zhu W, Huang C (2005) Gaussian random process and its application for detecting the ionospheric disturbances using GPS. Positioning 1:0

Zhao B, Wan W, Liu L (2005) Responses of equatorial anomaly to the October-November 2003 superstorms. Ann Geophys 3:693-706 